\title{
EL PROYECTO TEÓRICO Y CRÍTICO DE PABLO DE ROKHA
}

\author{
Ricardo Ferrada Alarcón \\ Universidad Católica Silva Henríquez, Santiago de Chile, Chile \\ rferrada@vtr.net
}

\section{RESUMEN / ABSTRACT}

El tema central de este trabajo focaliza su desarrollo en propuestas teóricas en el ámbito literario, hacia la primera mitad del siglo XX en Hispanoamérica, particularmente el proyecto que formulara el poeta Pablo de Rokha en su texto "La épica social americana", incorporado en su libro Arenga sobre el arte (1949).

La premisa que se postula es que "La épica social americana" constituye una apropiación del discurso totalizador de las vanguardias, proyectada en la imagen heroica del poeta, cuya escritura debiera considerar el contacto entre la cultura ilustrada y la cultural popular.

En ese contexto, el objetivo que se busca es recomponer tópicos y líneas de sentido que ordenan el discurso teórico planteado por de Rokha, atendiendo a los énfasis y conexiones con el discurso cultural y literario de sus tesis. Consecuentemente, el centro de la discusión conduce al empleo de conceptos y categorías de orden interdisciplinario, donde es fundamental la idea de apropiación, en vínculo con el contexto en que se produjo su texto.

PALABRAS ClaVE: vanguardia(s), discurso teórico, épica social, apropiación.

\section{THE THEORICAL AND CRITICAL PROJECT OF PABLO DE ROKHA}

The central theme of this work focuses on theoretical proposals in the literary field, towards the first half of the twentieth century in Hispanic America, particularly in Pablo de Rokha sproject developed in the text "La épica social americana", incorporated in his book Arenga sobre el arte (1949).

Our premise is that "La épica social americana" is an appropriation of the avant-garde totalitarian discourse, projected in the heroic image of the poet, whose writing should consider the contact between enlightened culture and popular culture.In this context, the aim is to recompose topics and the lines of meaning that order the theoretical discourse of Pablo de Rokha, attending to the emphases and connections with the cultural and literary discourse 
of his theses. Consequently, the center of the discussion demands the use of interdisciplinary concepts and categories, where the idea of appropriation is fundamental, in connection with the context in which the text was produced.

KEYWORDS: avant-garde, theoretical discourse, social epic, appropriation.

\section{PRESENTACIÓN}

El tema central de este trabajo focaliza su desarrollo en propuestas teóricas en el campo literario, hacia la primera mitad del siglo XX en Hispanoamérica, particularmente el proyecto que formulara el poeta Pablo de Rokha en su texto "La épica social americana", incorporado en su libro Arenga sobre el arte (1949).

De Rokha produjo una poesía de lenguaje inconfundible, traspasada por su experiencia y las tensiones sociales y artísticas de su época; también fundó un sello editorial y una revista, desde la cual ejerció su carácter polemista, cuyas ideas y reflexiones sobre estética y literatura constituyen formalmente un lúcido corpus teórico.

Considerando el alcance mayor de sus reflexiones, ese discurso cabe integrarlo a una de las líneas reflexivas que confluyen en el proyecto de constituir una teoría literaria hispanoamericana, en tanto elaboró distintas aproximaciones conceptuales que involucran su interés en articular arte, política, literatura, cultura ilustrada y cultura popular. Es inequívoco sostener, consecuentemente, que los alcances de sus propuestas tuvieron un curso anticipador a las actuales orientaciones críticas que resignifican el entrecruce de sistemas y prácticas culturales, a su vez, conduce a que se active un principio central de las vanguardias históricas: la relación entre arte y vida, en la figura del artista que desborda el espacio textual hacia lo cotidiano y contingente.

En ese campo de problemas, un primer eje de este artículo sitúa el espacio de discusión en que se inserta su trabajo - vanguardias-y la premisa de este artículo, enmarcada teóricamente en el concepto de "apropiación". A continuación, se abordan líneas de sentido de Arenga sobre el arte que convergen en la propuesta de construir una "épica social americana"; finalmente, se realiza el análisis de "La épica social americana", mediante una estrategia que busca establecer los tópicos que dan forma a la teoría rokheana. 


\section{SOBRE VANGUARDIA HISPANOAMERICANA Y EL DISCURSO CRÍTICO DE PABLO DE ROKHA}

La historia literaria evidencia que a comienzos del siglo $\mathrm{XX}$, el ideario de nuevas estéticas y el sentido crítico hacia la modernidad en el contexto europeo, tuvo como soporte no solo la llamada obra de arte en sentido estricto, sino que también logró impulsar sus elementos fundadores desde una forma textual propicia en el declarado "manifiesto", que explicitaba los principios que sostendrían el colectivo que los generó. Aquí son claramente referenciales los diversos "ismos" que instalaron las grandes transformaciones artísticas del siglo pasado; hablamos del futurismo, pasando por el cubismo, el dadá y su anclaje posterior en el surrealismo con sus múltiples variaciones y el despliegue internacionalista de su influencia. Esta es una materia sobre la cual hay aportes críticos sustanciales y diversos, no obstante coinciden en sostener la radicalidad de ese "nuevo" arte y que permite explicar, paradojalmente, el desplazamiento y las transformaciones de la llamada estética moderna ${ }^{1}$.

Si atendemos al ámbito literario hispanoamericano, merced al internacionalismo artístico, el primer tercio del siglo XX evidencia un desarrollo que muestra rasgos en cierto modo afines al contexto centroeuropeo, en tanto se expresó mediante textos programáticos una fuerte tendencia vanguardista, que da inicio a una nueva tradición estética, opuesta al modernismo mariano. No obstante, lo singular de ese momento consiste en que se trató de un proceso que manifiesta la pluralidad cultural de la región, del cual quisiéramos destacar dos variables y que centran el fondo problematizador de este trabajo ${ }^{2}$.

Primero, advertimos que gran parte del continente tuvo movimientos de vanguardia, los cuales declararon sus principios mediante proclamas o documentos, canalizados en revistas que identificaban sus propuestas, consecuentemente, debemos hablar de las vanguardias latinoamericanas. Pensamos en algunas como Actual, Amauta, Savia, válvula (sic), Mural, Prisma, Proa, Klaxon, Revista de Antropofagia, Revista de Avance, publicadas en diferentes países (México, Perú, Ecuador, Venezuela, Argentina, Cuba, Brasil). 
En segundo término, y en la perspectiva del (permanente) proyecto modernizador hispanoamericano, referir a los movimientos de vanguardia en las décadas iniciales del siglo XX implica revisitar no solo los distintos colectivos que los agruparan y sus proyectos específicos, sino además considerar su nexo con el pensamiento teórico y crítico que los fundamenta, en clara oposición al momento anterior. Acorde a lo que hemos señalado en el artículo "La vanguardia literaria: una instancia formativa del discurso crítico latinoamericano" (Ferrada 2007), las diversas proclamas y manifiestos contienen una estrategia de acción:

exceden una mera línea programática de escritura o de lenguaje estético en tanto discuten un orden social y cultural, de modo que, en el fondo, se trata de proyectos totalizadores, de tono exhortativo y confrontacional, provistos de una intención que implica resolver o superar las condiciones impuestas por las convenciones de época o simplemente el desgaste de lo novedoso "por lo novedoso", que termina siendo un lugar común. (124)

En interés del tema que centra este trabajo, solo mencionamos que esa condición que articula una propuesta teórica y el discurso crítico lo encontramos, por ejemplo, en el euforismo (Puerto Rico), el postumismo (República Dominicana), el minorismo (Cuba), el ultraísmo (Argentina), el estridentismo (México), el creacionismo de Huidobro en Chile. En su conjunto, estimamos que constituyen proyectos que intencionan el cambio de los procedimientos formales o expresivos, tendientes a imponer el sentido provocador de la obra para capturar la recepción pública, en virtud de que muestran un alto grado de disidencia respecto de la sociedad y los valores que la sustentan, particularmente en los círculos ilustrados y de poder, asumiéndose en ruptura con el "arte burgués" y con una alta sensibilidad social y cultural. Cabe reconocer en ellos, además, la similitud en el sentido de futuro y el nexo entre arte y la acción cultural con efectos políticos.

Desde la experiencia de lectura, es relevante destacar en esos colectivos su fuerte sentimiento de lo propio, ligado a problemas de la cultura nacional, por otra parte, impulsan un conjunto de ideas que, en ocasiones, tienen matices contrarios a las expresadas por otros colectivos al relacionarlos entre sí, cuestiones que ponen en tensión después de todo el sentido universalizador de sus programas. En resumen, es plausible entonces señalar que la actividad teórica vanguardista del primer tercio del siglo XX asume un carácter fundacional, a lo menos en dos dimensiones, esto es, el orden artístico-literario 
y el de la crítica, en tanto praxis de escritura que elabora un discurso sobre las condiciones expresivas de la obra.

En los hechos, los artistas e intelectuales no solo elaboraron orientaciones a las prácticas de escritura, sino que, además, elaboran un discurso que intenta dar cuenta de esa nueva producción. Es radical en este último proceso el modo en que se inserta el trabajo crítico especializado, desde el cual se proponen nuevas categorías que operacionalizan el análisis o logran observar la situación de contexto, donde hay nombres que dan el fundamento para una nueva fase en la cultura y la crítica latinoamericanas. Para ese momento, pensamos en José Carlos Mariátegui, Arturo Uslar Pietri, Mario de Andrade, Alejo Carpentier, Alfonso Reyes, José Antonio Portuondo, Pedro Henríquez Ureña.

El chileno Pablo de Rokha, si bien es mencionado ocasionalmente en las historias literarias desde ese ángulo, tuvo una presencia activa en ese proceso. Así, en su producción se advierte el diseño de una poética propia, asociada a la vanguardia, que actualiza en su escritura; también hay textos suyos de carácter autónomo, en orden a proponer e instalar una teoría estético-literaria, un sistema crítico, y que desarrolló en el marco de su actividad como artista e intelectual, comprometido con la realidad y la cultura americanas.

Un texto inicial que muestra esa línea de trabajo lo encontramos en la escritura fragmentaria de Ecuación. Canto de la fórmula estética (1929), no obstante -a nuestro juicio- tuvo mayor relevancia o repercusión "Estimativa y método", que sirve de introducción a sus poemas en un libro clave como fue la Antología de la poesía chilena nueva (1935), texto en que aparecen de modo embrionario sus ideas sobre arte moderno y clásico, la relación de fondo-forma, el arte popular. En parte de esa introducción expresa:

El arte moderno, es pues, la reintegración al orden clásico. Está significado por el desplazamiento de los elementos híbridos de la retórica y la anécdota; por la unidad de fondo y forma; y por una especie de humorismo descompuesto en tragedia, que formula las cosas eternas sin énfasis. [...] Ahora, el arte popular es la condensación inmediata del sentimiento colectivo: poder-tabú, voluntad de expresión, mito, costumbre, sino, espanto, poderío religioso pre-racial, expandiéndose en valores accidentales. Punto de partida del arte ARTÍSTICO, de EL ARTE POR EL ARTE. (de Rokha, 73-74)

Un hecho fundamental para promover su poesía, la discusión política, la crítica y la teorización surge a partir de la fundación de la Revista Multitud 
(1939), que a su vez transformó en un sello editorial propio ${ }^{3}$. Al igual que en publicaciones similares de la época, mediante ese medio impulsará sus propuestas y reflexiones con un discurso claramente ensayístico, en que articula materias estéticas, culturales y políticas, como su "Teoría de la diatriba" (volumen $\mathrm{N}^{\circ} 1$ ). Agregamos que aparte de esos tópicos, es recurrente su intento por establecer el rol social del mundo letrado, que tiene en potencia igualmente ideas que desarrollará en otros ensayos publicados allí:

El intelectual sirve, y sirve COMO INTELECTUAL, precisamente porque es intelectual, y no hay que tomarlo, COMO INTELECTUAL, PARA QUE CUMPLA TAREAS QUE NO SON SU TAREA. Esto es gobernar, gobernar para el pueblo. Porque es, eternamente, la masa obrera y campesina, el pueblo, los trabajadores, los explotados y los humillados del mundo, el pueblo únicamente el pueblo, quien se expresa en los intelectuales. (1939, Multitud $\mathrm{N}^{\circ}$ 7; en Rozas, 2014, 31)

En esa misma línea, destacamos su libro Morfología del Espanto (1942) editado en Multitud, donde incorpora la "Teoría del arte proletario", con una clara referencia ideológico-política de carácter marxista.

Acorde con nuestro tema, el corpus de mayor densidad y articulación conceptual aparecerá en esa misma editorial. Nos referimos a su libro Arenga sobre el arte (1949), cuyo diseño se produjo hacia 1947, compuesto por ensayos sobre teoría estética, donde destaca "La épica social americana", que organiza en definitiva sus ideas en tanto programa de escritura y una propuesta de acción. También incorporó poemas, entre estos Carta magna de Chile, que incluye el texto "Teogonía y cosmología del libro de cocina", cuyo título cambió de Rokha por "Epopeya de las comidas y bebidas de Chile" en su Antología, 1916-1953, editada por él mismo (Multitud 1954)4.

3 Revista Multitud se mantuvo durante casi un cuarto de siglo. Antes había fundado Numen (1920), Dínamo (1922) y Agonal (1927). Remitimos a Daniel Rozas y el libro Pablo de Rokha y la revista Multitud. Santiago: Das Kapital, 2014.

$4 \quad$ En Aventuras y Desventuras de "ARENGA SOBRE EL ARTE” (sic), última sección del libro, Pablo de Rokha expresa un hecho revelador: la publicación del libro fue rechazada en 1947 por Editorial Claridad, sello editor que formó y dirigió el español radicado en Buenos Aires Antonio Zamora, por considerar que era un texto marxista, a pesar de que este último era un militante activo de izquierda. También menciona de Rokha las lecturas poéticas y la difusión de sus tesis de "La arenga ..." en Argentina. Zamora fundó también la Revista Claridad, como parte de un proyecto cultural de izquierda. Remitimos a Florencia Ferreira de Cassone Claridad y el internacionalismo americano. Buenos Aires: Ed. Claridad, 1998. 
La pregunta de fondo que hacemos, entonces, surge de interrogarse sobre cuáles son los supuestos conceptuales que se articulan en "La épica social americana "y le dan sentido a la actividad poética, según la tesis rokheana; desde otro nivel, es pertinente pensar en qué líneas de sentido convergen o (se) entrecruzan en el discurso, que conducen a generar tensiones sobre los marcos referenciales, que validan (o no) la pertinencia y posibilidad cultural de la teoría propuesta en el texto.

La premisa que postulamos sostiene la idea de que "La épica social americana" de Arenga sobre el arte constituye una apropiación del discurso totalizador formulado por las vanguardias y la proyecta en la imagen heroica del poeta, cuya escritura debiera considerar el contacto entre el sistema cultural ilustrado y el espacio cultural de raíz popular.

En ese contexto, el objetivo que se busca es recomponer las líneas de sentido que ordenan el discurso teórico de Pablo de Rokha, atendiendo a los énfasis y conexiones con el discurso cultural y literario de sus tesis. Consecuentemente, el centro de la discusión conduce al empleo de conceptos y categorías de orden interdisciplinario, donde es fundamental la idea de apropiación, en vínculo con el contexto en que produjo su teoría.

El concepto de apropiación adquiere un valor teórico y operativo en este trabajo; su primera entrada entendemos refiere a un proceso en el que un sistema cultural actúa sobre la base de materiales prestados para proyectar su propio desarrollo, de modo que antepone el problema de la división o las diferenciaciones entre sistemas. La fórmula habitual es pensar en un grupo que adopta productos o tendencias dominantes, a sus propias expresiones culturales (modas, estilos, códigos sociales, lenguajes). En la práctica, en el análisis se hace visible la relación yuxtapuesta entre sistemas o discursos y que se integran en nuevas formas de sentido, o la desviación de los habituales, en síntesis con los adoptados. En gran medida, esto nos evoca el proceso de transculturación que formulara Ángel Rama, con las atendibles restricciones de su empleo.

No obstante esa idea general, Roger Chartier en El mundo como representación (1999), afirma que estudiar la apropiación, "apunta a una historia social de usos e interpretaciones, relacionados con sus determinaciones fundamentales e inscritos en las prácticas específicas que los producen" (53). A su juicio, eso permite tomar distancia para advertir que las relaciones culturales están organizadas no solo por oposiciones o contrastes entre la elite y el pueblo, por ejemplo, o dominadores y dominados, antes bien, debiera atenderse a la circulación de "objetos, formas, códigos y no grupos", que nos llevan a 
las estrategias de representación colectiva, generadas por el modo en que se inscriben las interpretaciones en la sociedad, materia que en definitiva potencia la construcción de la historia cultural, cuyos elementos significativos están delimitados no solo en campos de saberes, antes bien, en agentes que construyen sentido.

Definida de esa manera, es fundamental atender a que si el interés investigativo apunta a las formas de representación, inevitablemente conduce a pensar en el modo específico en que se producen; asimismo -agregamos-, en el dominio técnico y la voluntad autoral que impulsa la circulación de los objetos, que por cierto no neutraliza la intervención de quienes interpretan las significaciones de aquello que se representa.

En gran medida, esto conecta con una línea teórica de Michel Foucault, que refiere particularmente a su planteamiento de apropiación de los discursos (El orden del discurso 2002), en tanto estrategia de control ejercida por individuos o instituciones, constituyendo una forma de poder. En realidad, atendemos en este ámbito a cómo elabora el concepto, para situarlo luego en tanto posibilidad de un espacio en el cual se producen los sentidos en la cultura, en virtud del acontecer social. No obstante, esa apropiación también se definiría como mantener el secreto de un saber que se niega a otros su intercambialidad (42). Las condiciones que marcan esta última óptica disponen el problema de cómo se forman las sociedades de discursos, cuya orgánica mayor encontramos en las doctrinas y disciplinas científicas.

En el medio chileno, Bernardo Subercaseaux (2004) recurre a la idea de "apropiación cultural", para explicar el surgimiento de la vanguardia en Chile y por extensión en Latinoamérica, en cuyas estéticas se activaron "apropiaciones" de los medios expresivos, originados en los diversos países europeos donde se produjo el quiebre o ruptura artística hacia comienzos del siglo XX, a diferencia de la tradición modernista en la cual operó más bien un sentido imitativo del llamado lenguaje literario.

El concepto de "apropiación", en el caso de Pablo de Rokha, conduce a observar las formas de discusión que incorpora en su discurso -con las herramientas intelectuales provenientes de la filosofía, la estética, el sicoanálisis, las teorías de la vanguardia-, en cuyo centro sitúa al poeta en el rol de resignificar la cultura popular, para producir modificaciones en los determinismos históricos. Es el fondo que le llevó a formular su épica social americana. 


\section{LA ARENGA SOBRE EL ARTE Y LA CONSTITUCIÓN DE "LA ÉPICA SOCIAL AMERICANA"}

La propuesta estético-literaria de Pablo de Rokha dialoga con diversas variables, provenientes de un proceso cultural y literario de profundas y determinantes transformaciones. En la perspectiva presente, es indiscutible su cercanía con las poéticas de vanguardia, que enriquecieron el panorama artístico y la discusión en torno al oficio del escritor, en un ensamble simultáneo con las posiciones del discurso político-ideológico; en su caso, responde a los conflictos derivados de las tensiones sociales de época, que le llevaron a su adscripción ideológica. Para los estudios críticos, significa considerar la toma de conciencia respecto de esa producción literaria, cuestión que demandó una teoría que aportara a la interpretación de esa nueva literatura, desde un fondo americano.

Otra variable específica de ese contexto se conecta con un aspecto formal de su discurso -la arenga-, que es posible enmarcar en la tradición del manifiesto artístico, cuya praxis a inicios del siglo XX sostuvo el ideario de principios y elaboraciones teóricas; en ese entendido, constituyó una vía de expresión programática hacia un receptor masivo al cual se busca influir.

Entonces, textualmente, la Arenga sobre el arte exhorta a la acción poética y procura dar las bases de un proyecto escritural. Esto obedece, primero, a que el fondo temático se apoya en la argumentación de ciertas proposiciones de orden programático, que dan precisamente el tono exhortativo a las ideas (una arenga). Su fundamento tendría razones filosóficas, políticas, históricas y literarias, que respaldarían la decisión de ahondar en la contingencia social desde la creación poética; en segundo nivel, hay un desarrollo orientado a la exposición de conocimientos hacia un receptor ideal, formas conceptuales que definen una estructura de pensamiento y constituyen un teoría, es decir, un modelo desde el cual se explica el orden social y artístico, un saber que se entrega al lector.

Que el libro se organice mediante ambos tipos discursivos, sin que el argumento excluya la difusión de ideas, se explica por el interés mismo del proyecto de La Arenga, la cual debido a su carácter de programa, no busca construir solamente un modelo estético, sino que más bien tiene un propósito fundamental: la exposición de planteamientos teóricos, que debieran lograr un efecto pragmático en el escritor. Por otra parte, el lector ideal debiera poseer un marco de conocimientos amplio para asumir la labor de interpretación de los componentes temáticos: historia (universal y nacional), economía; 
religión, filosofía, sicología, estética, arte, literatura, poesía. Es decir, requiere manejar un marco de saberes complejo y múltiple, que lo sitúan en el campo del intelectual ilustrado. En definitiva, el receptor del mensaje rokheano se encuentra ante la necesidad de dominar conceptualmente variados campos, que no solo le lleven a aprehender el sentido programático para incorporarlo a la escritura, sino que requiere también asumir un conjunto orgánico de valores que provienen, esencialmente, de la filosofía marxista a la que adhiere el autor.

El lugar de esta obra en la producción de un saber en diálogo con la estética, la política, la reflexión crítica y la producción literaria, está dado tanto por sus temáticas -el contenido o fondo, problema que el mismo de Rokha apunta y desarrolla en un capítulo-, como también en la forma de su discurso, esto es, una modalidad argumental-expositiva desbordada por su retórica. Desde esa condición discursiva, se observa cómo pone énfasis en el espacio americano, aunque sin desvincularlo de los conflictos ideológicos $\mathrm{y}$ tensiones culturales del mundo occidental a mediados siglo XX, cuestión que explica su tono en que aparece la ironía, la mordacidad, la convicción mesiánica del mensaje, originado por el rechazo al llamado modelo capitalista y a un arte que responde a un afán intelectualista o de servilismo al mercado 5 .

Así, concebido como un discurso, el estudio y análisis de la Arenga concierne en verdad al ámbito estético e ideológico, es decir, opera allí una sobreposición disciplinar y de orden político, para integrar las dimensiones contextual y social, que aparece justificada por razones artísticas e históricas. El discurso rokheano articula por tanto líneas de desarrollo en una orgánica que direcciona y transversaliza su trabajo, plasmado en una escritura con un centro subyacente que sostiene su formulación teórica, en resumen, una matriz conceptual cuyo fondo plantea una visión del artista, su quehacer y su vínculo con la sociedad.

Desde esa premisa, es válido plantear que los apartados tienen conexiones internas, las cuales configuran o aportan al dispositivo de intervención creado por de Rokha en su Arenga. De este modo, es destacable cómo, a partir de los títulos, hay una aproximación inicial de los tópicos y componentes temáticos que llevan a construir "La épica social americana", que en la perspectiva actual,

Este último elemento que discute, sin duda, es muy anticipador de discusiones posteriores, asociadas a la idea de industria cultural, proveniente de la teoría crítica de Theodor Adorno y Max Horkheimer, quienes constituyen precisamente el referente teórico obligado de la crítica cultural. 
dan forma a un relato que permite recomponer las variaciones culturales y políticas de la época. Destacamos la "Introducción a una técnica del espíritu desde el arte"; "El arte como lenguaje social y expresión histórica de lo humano y «lo divino»"; "La gran batalla por la forma: Contenido y Continente"; "El fenómeno político de la belleza"; "El arte de los sirvientes"; "La bestia herida"; "Terror - Sueño - Dolor - Mito - Amor - Verso".

Es claro que las líneas de sentido que articulan las conexiones abren campos y perspectivas conceptuales, que operan en la forma taxativa asumida por de Rokha para constituir los criterios que le dan certeza a sus afirmaciones. La elaboración de sus ideas tiene el supuesto de que procura informar al lector, en la medida en que se ha apropiado de un rol es un yo que enuncia y sitúa un parámetro que fija su discurso en la historia, mediante el cual establece de modo declarativo una filiación ideológica, que daría respuesta -a su juicio-, a las tensiones epocales en su plasmación artística.

Un componente fundamental en ese proceso es su diferenciación entre ciencia y arte, cuyo carácter opositivo lo inscribe en un modelo dialéctico para explorar y representar la experiencia empírica, descartando la posibilidad de asociar el arte con un simple ejercicio intelectual, pues asume que, desde el mundo imaginario, aproxima a la complejidad humana. En "Introducción a una técnica del espíritu desde el Arte" señala: "En la ciencia no hay imágenes, y en el arte no hay ideas, porque las imágenes son el lenguaje único del arte, $\mathrm{y}$, cuando hay ideas, no funcionan como ideas, sino como arcaicos conceptos soñados (las imágenes metáforas)" (60). En más de una ocasión, opondrá la racionalidad científica, incluso filosófica, ante la arracionalidad artística, que pone en analogía con la religión, pues tendrían el mismo origen síquico, en tanto responden a la necesidad de dar forma a contenidos que exceden el nivel consciente.

La singularidad de esa delimitación radica en que vemos operar un desplazamiento de la dialéctica histórica tradicional, o más bien, de los términos opositivos que integran esa dialéctica, para situarlos en el campo artístico: "La belleza no existe en la naturaleza sino potencialmente, como en el hombre. La belleza es la solución dialéctica (la negación de la negación), del conflicto hombre-mundo desde el ángulo del subconsciente" (69; las cursivas son nuestras), con lo cual amplía incluso las posibilidades de análisis al considerar categorías freudianas. O las complejiza aún más, cuando reafirma que el arte es una solución estética al conflicto del individuo y el universo (87), donde el desafío consiste en alcanzar un lenguaje universalizador en las 
formas artísticas, pues pone en contacto lo humano y el sentido trascendente de su historia, que excede el mundo individual.

En ambas premisas, observamos que rompe con orientaciones de un paradigma idealista en la génesis de la producción artística, para situarla en la materialidad de la historia. Sin embargo, ocurre que también propone una explicación en que el arte deja de ser un epifenómeno, acorde a la perspectiva entregada desde la estética marxista. De hecho, en "El arte de los sirvientes" postula que los estilos han sido un producto proveniente del trabajo de artistas y maestros, quienes rompen o procuran revertir el dominio de las estructuras sociales; en la época moderna, ese arte arrancaría en gran medida de la desolación social y personal que terminó - dice-, con la protesta en la bohemia. En "El fenómeno político de la belleza" explicita más claramente el núcleo desde el cual concibe su pensamiento, en una suerte de encuentro con el origen de las formaciones artísticas: "[...] el arte emerge del subsuelo social, como la expresión social de lo vital y toma la forma política de insondable personaje formidable que le imprime su creador, reflejo del ambiente ..." (122).

El despliegue de ese trabajo de artistas y maestros proviene -en su conceptode una voluntad creadora, cuya operatividad básica parte de su conexión con la experiencia, inserta en "la materia social", que en definitiva demanda se la organice para imponerle un sentido: "el artista ha de dar la forma equivalente al fondo, la forma correspondiente al fondo que la sociedad le entrega ..." (91). En este caso, hace explícito el vínculo indisoluble de forma y fondo, que entiende es un falso dilema separar, por el contrario, teóricamente el logro de una obra artística se alcanza en la unidad de esa dicotomía, cuestión en la que subyace el desafío de encontrar ese fondo, como a su vez el lenguaje equivalente que traduce su sentido.

Ese punto deviene, por lo mismo, en una revelación conceptual de su teoría estética, si atendemos a que resuelve una dicotomía: en la vida social se generan los contenidos a los cuales el artista da una forma, una tesis que pone en cuestionamiento e invierte la noción del genio creador que deja correr libremente su conciencia, para experimentar con la forma que materializa su proceso imaginativo. En esta idea descansa su crítica hacia los postulados de las vanguardias, que si bien valora por su irrupción con nuevos lenguajes, termina rechazando, por el apego que mostraron hacia las teorías del inconsciente, las cuales restan la voluntad de un proyecto creativo, además del lugar social que ocuparon finalmente en el siglo XX, esto es, en la cultura de elite, que identifica con el mundo burgués. 
Para de Rokha, entonces, si el arte denota un rasgo diferencial entre el hombre y el mundo, la solución sería rebasar esa tensión, para lo cual postula un estilo militante, que arranca de su convicción de que todos los grandes poetas de todas las épocas son políticos: "la poesía adquiere la significación política, artístico-política, en razón directa de ser función pública, es decir, social y beligerante ..." (124).

El sustrato que enmarca ese intento de (re)posicionar la poesía y el sujeto empírico que la escribe, hace válido sostener que el discurso rokheano, desde su particular ámbito epistemológico, aporta un marco de ideas al discurso teórico hispanoamericano, pues en su taxativo argumento propicia una instancia fundacional, tanto del arte como del artista escritor, que discute e interrumpe el ímpetu personalista y subjetivador proveniente de la estética de origen modernista:

[...] quien construye su Torre de Marfil y se esconde dentro de ella, haciendo "el arte por el arte", haciendo arte puro", haciendo esteticismo y arte para las minorías, en contraposición a un arte para las mayorías, aunque las mayorías no lo entiendan, es decir no lo intuyan, se queda fuera de la historia [...]. (95)

Ese arte para las mayorías, si bien puede situarse en los límites conceptuales de un arte de masas, lo hace converger, en su línea profunda, con un tópico o variante en la que proyecta el sentido originario de la poesía, esto es, una actividad ritual y totalizadora que se inserta en la memoria colectiva, de modo que se constituye en una tradición que expresa el encuentro del hombre con su lenguaje, la sociedad y su propia historia:

El arte de hoy por hoy en América ha de ser una gran épica americana, porque el denominador común de América, atroz y popular de índole, arrastra al gran poeta hacia las vías públicas del mundo y le da el material ardido del estilo, quemante de multitudes y de muchedumbres trágicas, que requieren hablar al siglo. (94)

En ese campo de discusión, centrándonos en el proyecto de "La épica social americana", se manifiesta un fuerte énfasis de lo nacional, pues esta concepción reveladora sostiene la idea de una "acción poética", que pone en cuestionamiento los principios ordenadores de las metrópolis culturales. Ese tono local converge en su anticipador encuentro con la cultura popular, la cual no solo enaltece, sino que se apropia de sus conflictos, donde su expectativa es que "el gran poeta social contemporáneo" traduzca las marcas que definen 
su epopeya vital. En esos términos, su (contra)discurso conduce tanto a la superación del individuo, como también a la propuesta de una literatura en que predomina la referencialidad de los contextos, cargados simbólicamente con imágenes de la vida comunitaria y la vida pública del sujeto colectivo, que converge finalmente en la superación del lirismo poético.

Lo que hace de Rokha entonces, en función de sus propias palabras, es promover una nueva concepción del arte, con conciencia de su historia y de su pueblo, donde el objeto artístico esté destinado no solo para algunos, sino para todos, ya que aquel arte debe manifestar, "arracionalmente", las inquietudes que afectan al ser humano.

En síntesis, el desarrollo de los tópicos en la Arenga dan cuenta de temáticas heterogéneas en el discurso rokheano, dispuestas en una visión de permanente divergencia y contraste, propiciada por el fondo crítico de los argumentos. Resulta muy evidente en ese plano la presencia de un conjunto de supuestos ideológicos que activan la superposición del arte, la cultura, la historia, la sociedad, el estado, el pueblo, la religión, a partir de una base empírica y que provee al poeta los contenidos para su ejercicio poético. En términos de la materialidad del poema, este registra entonces en las palabras rasgos de época, que la voz del poeta recoge tensionando las visiones de la realidad en su proyecto de escritura.

De ahí que, en su visión, el arte constituya una búsqueda consciente de medios expresivos, puestos al servicio de la crítica social; por otra parte, las trasformaciones que experimente entregan, más que ideas, imágenes de la realidad en un nivel superior de la conciencia humana. Esto incluye la fuerza expresiva de lo que denomina la "arracionalidad", con lo cual desplaza la premisa del inconsciente impulsada desde el surrealismo, donde los lenguajes se potencian en su capacidad simbólica y manifiestan un tipo de verdad que emerge desde la lucidez profunda del artista. Esto nos evoca, de algún modo, la estética creacionista de Vicente Huidobro, quien veía en el poeta al creador de realidades, la acción hiperlúcida en el proceso de escritura que debe conducir a una realidad antes no imaginada.

\section{LA ÉPICA SOCIAL AMERICANA EN ARENGA SOBRE EL ARTE}

Según las páginas de inicio, se ha establecido que Pablo de Rocha desarrolló una opción artística, basada en una reflexión teórica en distintos momentos y 
publicaciones. La muestra clave en esa teorización la encontramos en su libro Arenga sobre el arte, cuyas secciones constituyen un discurso que propone nuevas fórmulas para la práctica literaria.

En este apartado, se entrega la articulación del análisis anterior, que mostró los tópicos generadores de la Arenga, atendiendo a sus líneas de sentido, y que conducen por último a develar una concepción dialéctica de la estética. Ahora se trata de acotar con mayor precisión los principios de "La épica social americana", los cuales implican un modelo teórico que procura totalizar un concepto de la poesía, a su vez, un proyecto de intervención de la realidad, considerando su carácter de manifiesto; es así que propone la creación de un espacio poético, cuya referencia ha de ser -a su juicio-, el contexto sociocultural y el conservadurismo burgués.

Las formulaciones que sustentan "La épica" son posibles de observar en la apertura del texto, con una declaración que sintetiza la respuesta teórica de fondo:

Cansada la escritura continental del lenguaje servil de "el arte por el arte", requiere no tampoco el lenguaje servil del profeta aciago y arcaico de bohemia, introvertido por ser el sacerdote del inconsciente, sino la imagen multitudinaria del gran poema contemporáneo, hijo del pueblo, y del gran poeta social contemporáneo, criado con espanto en sus entrañas, en las entrañas de las masas. (160)

Acorde con ese planteamiento, la actividad poética y la intervención artística de la realidad convergen, por tanto, en la búsqueda lúcida de los medios que superen al "sacerdote del inconsciente" -una alusión a la escritura surrealista-, para llegar a un arte de ruptura y contestatario, en tanto el poeta consciente impone una perspectiva globalizante de la época al objeto artístico, a partir de su inserción en la materialidad de la historia:

El gran poema de combate, de frente de combate por el cual luchamos entre la pólvora del tiempo, el gran poema de combate (que eternizará el combate en la forma clásica), va a reflejar la época heroicamente en el lenguaje popular, panfletario y subversivo de las admoniciones eternas $[\ldots]$... (164)

A partir de sus afirmaciones, es posible sostener que al elaborar un modo de situarse ante la realidad, asume también que el artista deba exhibir plena conciencia de su labor en la historia, configurándose así esa poética de la acción en la idea teórica de la "gran épica social americana", que entendemos 
arranca de su concepción dialéctica de la belleza y el arte. En esos términos, fundamenta el origen de su épica:

Por eso hacemos una gran épica social americana, como reflejo y sublimación de América, sin regresar a lo épico-académico [...] alcanzando lo heroico proletario en la oposición a lo lírico-burgués, a lo subjetivo-burgués, a lo íntimo-burgués, retratando la heroicidad trágica de las masas obreras en lo bello público y clásico [...]. (163)

Según se deduce, la propuesta de construir su "épica social americana" parte del reconocimiento y sentido enaltecedor del mundo social, que eleva a una categoría superior. Desde ese ángulo, es un moldeamiento en cuyo centro pone la incorporación de un sujeto víctima de las diferencias sociales, violentado precisamente por los circunstancias y determinaciones históricas y económicas, con la finalidad de engrandecer y visibilizar su fondo humano y que se constituya en un componente ideológico, donde el artista asume la voz épica de un colectivo.

Esa variable da cuenta de un diálogo entre el proyecto rokheano y la crítica de la cultura, entendida en su caso como la discusión contra el uso de formas estéticas anquilosadas y un modelo hegemónico de sociedad, a partir de la nueva definición de arte que él mismo construye. En su modelamiento, la fisonomía del poeta está fuertemente ligada a su rol provocador, potenciando a su vez en la escritura una metapoesía que pone en cuestión las posibilidades de la palabra en el poema; esto se traduce en la posibilidad de romper con las formas literarias tradicionales, no obstante, si bien emplea un tono renegador, propone integrar al nuevo lenguaje el peso de lo clásico, idea que sostenía con anterioridad a su épica:

Pero no hagamos versos o sonetos feudales [...], no nos vaciemos indignamente nosotros dentro de las formas arcaicas, caducas, pasadas como los borrachos en las plazas públicas [...] al conquistar un vocabulario lo hagamos con dirección a la historia apuntándola a lo clásico. Un arte machuno y sombrío por la tragedia americana [...] No melancólico: trágico dramático; no lírico: épico [...]. (162)

Con esa plataforma teórica, asigna al poeta el rol de constituirse en un partícipe de la historia, que enaltece a la categoría de héroe público, expresada en una acción que interviene poéticamente la realidad. Así, el carácter épico de la poesía dispone el desafío heroico de su actividad, en la cual se tensiona el lenguaje y el campo de ideas que movilizan las palabras, en la medida en 
que se comunica, antes que un momento lírico, un estado del orden social y cultural; en resumen, es una poesía que no evoca el tono íntimo, sino su origen colectivo y clásico, en que la voz del poema aproximaría a las tensiones que orientan el transcurso histórico en el acto de leer.

Al concebir al artista como un héroe, se propone un modelo de arte distanciado de un idealismo subjetivo, en tanto su voz revela el espíritu colectivo de su pueblo; en este sentido, plantea: "el gran poeta de hoy, explotado azotado entre los explotados y entre azotados sociales y explotadores de trabajadores, o es la voz de la clase obrera y del pueblo, o no existe" (172). Ante esto, subyace en el ejercicio de esa poética un componente ético que condiciona la estética de la palabra, es el "fenómeno político de la belleza" del cual habla en una sección clave de la Arenga.

Respecto de la cita anterior, se evidencia como proposición el planteamiento de un arte heroico, hecho por hombres con conciencia del sufrimiento producido por violentas condiciones de trabajo. Ello indica que un aspecto de la propuesta rokheana está determinado por la necesidad de una poesía heterodiscursiva, en el sentido que es social, histórica, política cultural y crítica, particularmente frente a la visión idealista del "arte por el arte", lo que desemboca en una forma activa de plantear el discurso poético. Mario Ferrero en su artículo "Pablo de Rokha" (Revista Atenea 1968), respecto de la obra poética rokheana, afirma:

La suma de estos factores, fundidos en un proceso unitario, contribuyen a dar contenido y estilo a lo que se ha dado en llamar el gran barroco popular americano, "la gran épica social americana" de Pablo de Rokha. (249)

La revolución del arte en de Rokha, es entonces -siguiendo sus palabrasla revolución de la forma y del fondo de la forma, que se activa mediante la inclusión de elementos de la cultura popular, que pasa a representar el mundo simbólico de mayor trascendencia para la producción artística. En ese contexto, esa forma cultural funciona como un referente estético y de un eventual conocimiento para el receptor, cuya orientación de lectura debiera recomponer los diversos elementos que integran el significado del texto y conducen la trama de posibles sentidos, en que su validez surge de su arraigo primordial en la historia y que lo vincula con su propia esencialidad:

El arte popular es el único que existe y es el único arte que existe, porque el arte popular es el arte logrado como arte en todos los 
tiempos, porque todos los pueblos lo influyen como triunfa la forma nueva sobre la forma vieja y se impone, y como fue el artista el que dio la forma material que dieron los pueblos, los pueblos entienden al artista como un líder y no como un lacayo, es decir, como un creador de forma". (161, nota 36)

Así pues, la función revolucionaria del arte y la poesía estaría dada por la intención de quien escribe el poema - la voz que enuncia en el texto-y que asume la responsabilidad de provocar al lector, abriéndole un modo de ver la historia y la cultura. De Rokha, puede observarse, insistirá en que la época se expresa heroicamente en la inclusión del lenguaje popular y la subversión de los sujetos, de la cual solo el artista puede hacerse cargo, por el hecho de tener el control de la forma y el dominio superior del lenguaje; ello hace evidente que el artista sea un sujeto con poder, mediante el cual disputa y contradice el intento de desplazar lo genuinamente popular.

Desde esta perspectiva, "La épica social americana" se formula a partir de un proyecto de reivindicación del arte y del artista, basándose en las premisas de su Realismo Popular Constructivo, que se deshace de las formas meramente esteticistas para construir un nuevo canto heroico, que considera la expresión del espíritu del pueblo y de la época, conformando un nuevo proyecto, un [...] “Arte Grande, popular y épico [...] (170).

Entonces, la propuesta teórica de Pablo de Rokha se constituye como un proyecto fundador con una visión del artista, quien debe ser consciente de la sociedad, sus necesidades y sus realidades, donde su discurso se compondría de elementos épicos utilizados a partir de ciertos recursos retóricos. Por último, "La épica social americana", la acción poética que ella significa, se sintetiza en la palabra exhortativa en que se funde al yo autoral la declaración de su ideología, su "testimonio de parte", en los términos empleados por Mariátegui (1928), comprensible por una época en que se demandaban definiciones taxativas:

[...] invito a mis hermanos de clase, los obreros de la creación artística, a hacer creación artístico-política como frente de combate social, obrero, mundial, contra "el arte por el arte" que es el arte granburgués de los explotadores de los trabajadores del mundo. Arte de esclavos, nó, arte de lacayos, nó, arte de rebeldes, sí, con ideología, un arte marxista de hoy, acometedor y heroico. (174) 
En ese contexto, el poeta debe asumir su campo de poder y opción ética con el propio discurso; es un trabajador intelectual -acorde a de Rokha-, que se mueve en la ética de las subjetividades, en que el reconocimiento de los conflictos en el espacio social hace entrar la necesidad de cautelar o contener el dominio sobre otras subjetividades, para instalar formas de expresión que excedan la subordinación al esteticismo literario. Es el espacio cultural donde el escritor entra en vínculo con la posibilidad de formas rupturistas de representación, que muevan el campo de las acciones reales, anclándose con las grandes tradiciones del arte:

buscamos lo clásico en lo contemporáneo, porque lo clásico entraña la victoria de la forma exacta sobre la forma desviada [...]; porque lo clásico, que no es premonitorio, incluye todos los modos de ser del arte anticipando la sublimación histórica de las épocas a las épocas fijando definitivamente sus rasgos totales $[\ldots]$ es eternamente el descubrimiento general de la belleza, contra lo académico subordinado al andamiaje que desechó lo clásico ...cuando lo clásico superó todas las técnicas. (163)

El sentido colectivo de su declaración -la búsqueda-incorpora un problema y una paradoja, que en definitiva configura un rasgo central de las vanguardias, de cuyo discurso de Rokha se apropia y actualiza en el contexto americano: la vinculación del arte con los lenguajes del mundo contemporáneo, una tensión que lo condujo a considerar la praxis social cotidiana y la búsqueda de la belleza, oponiéndose a una orientación que desestimó lo clásico. Por otra parte, su propuesta conduce a una idea de esa misma vanguardia, esto es, el proyecto de aproximar el arte y la vida, que le llevó precisamente a considerar el mundo popular, que conecta precisamente con los rasgos de la trascendencia histórica.

\section{CONCLUSIONES}

En la perspectiva del (permanente) proyecto modernizador de la región, la discusión teórica y las prácticas artísticas de las vanguardias hacia el primer tercio del siglo XX constituyeron un momento fundacional. El tránsito que tuvieron resulta inevitable ponerlo en diálogo con los contextos particulares de las zonas en que se expresó esa búsqueda de lo nuevo, cuestión que, razonablemente, explica las diferencias en los proyectos programáticos que 
sostienen las prácticas de creación artística. En ese entendido, manifiestan, antes que una mímesis cultural de formas expresivas parisinas o europeas, un proceso en que se las hace propias, con las múltiples derivaciones en teorías particulares, que manifiestan paralelamente un pensamiento crítico.

Ese rasgo induce a plantear que las vanguardias en Hispanoamérica tensionaron la (eventual) autonomía de la obra, que deriva, en términos amplios, a una consigna que impulsó la vanguardia -fusionar el arte y la vida-, además de una sensibilidad y actitud comprometida de nuestros artistas e intelectuales, quienes mediante agrupaciones o documentos formulan una estética transformadora que deviene en un hecho social y político, materia en la que hay acuerdo pleno en la historiografía especializada. Fue la provocación que desinstala la sensibilidad automatizada del espectador, alterando las formas y códigos estéticos, en que los espacios de la elite se desplazan hacia el sujeto cotidiano y el arte de raíz local. Desde esa mirada, se manifiesta una constante búsqueda de lo nacional e identitario, pues esta concepción reveladora sostiene la idea de una "acción poética" que refleja la esencia del hombre americano, en tanto constituye un modo de ser, ver y hacer arte, dejando de lado los cánones establecidos de las grandes metrópolis culturales.

Acorde con el análisis previo, el discurso teórico que propuso Pablo de Rokha tiene una dirección que articula esas concepciones, cuestión que sabemos hizo ya a partir de los años 30 del siglo XX. Un texto fundamental en esta materia es la sección "El fenómeno político de la belleza" de la Arenga sobre el arte, que opera en una suerte de matriz orgánica de sus planteamientos, o el argumento sobre el sentido opuesto de fondo y forma que dispone en un vínculo complementario, para sostener que el artista da forma a la realidad, de modo que los medios expresivos exceden la arbitrariedad creadora. Si hacer arte implica dar forma a los contenidos culturales e históricos, el poeta "le imprime su conducta" (de Rokha), de modo que es el protagonista del escenario social. Eso implica retomar la tradición del poeta inserto en la realidad, cuya palabra acoge las circunstancias del mundo empírico y el lenguaje que identifica el pueblo en su experiencia vital e histórica.

Por lo mismo, de Rokha formula un discurso teórico que sitúa al poeta en la categoría de líder social y cultural, en el desafío de continuar con la tradición épica, que en su concepto significa alcanzar el contacto genuino con el arte popular, el único que -asegura-, existe en todos los tiempos. Desde un imagen recursiva del tiempo cultural, declara encontrarse en la búsqueda de "lo clásico en lo contemporáneo", por cuanto ese arte significa la fusión perfecta de fondo y forma, cuestión que nos sitúa en una perspectiva distinta 
en la consideración del pasado y la posibilidad de que en lo actual (léase vanguardia) se evoque ese pasado.

La palabra mayor de su teoría se origina en su intento por superar la estética del "arte por el arte", además de contraponerse a todos los movimientos e ideologías vigentes en su época. En ese contexto es que propone la imagen del gran poeta contemporáneo, impulsada desde el sentido del canto popular heroico -la "conquista de lo clásico" en lo contemporáneo. Así revierte la experimentación poética y la independencia del objeto mediante "La épica social americana", proyectando ese proceso en la función liberadora del poeta. La construcción de su discurso -creemos-impone un rasgo diferenciador con la escritura de vanguardia, en un distancia análoga a la que mostraría César Vallejo, en tanto ambos sospecharon de lo novedoso-experimental en poesía.

La orgánica de ese dispositivo intelectual hace posible sostener entonces que "La épica social" constituye una instancia teórica y crítica, que vincula el mundo simbólico con la necesidad de los cambios sociales. En razón de ello, se concibe como proyecto de acción poética en el marco de una vanguardia de inspiración popular, la cual hace emerger la presencia de un sujeto activo, que afirma la posibilidad de una transformación en la sociedad, considerando diversas variables discursivas e históricas que la tensionan. Es función del escritor, entonces, establecer una conciencia crítica en el lector, en orden a completar el proceso transformador que impulsa la palabra.

En tal sentido, su propuesta se enmarca a su vez en un ámbito más amplio todavía, esto es, el intento de producir teoría literaria en y desde Hispanoamérica, de modo que forma parte de quienes iniciaron ese proyecto. Hablamos de Pedro Henríquez Ureña, Alfonso Reyes, José Antonio Portuondo.

\section{BIBLIOGRAFÍA}

Corpus

de Rokha, Pablo. Ecuación (Canto de la fórmula estética). En Poéticas del paisaje. Dirección editorial Guido Arroyo. Santiago: Eds. Alquimia, 2016.

Obras inéditas. Santiago: Lom, 1999.

Epopeya del fuego. Selección, prólogo, notas y bibliografía de Naín Nómez.

Santiago: Universidad de Santiago, 1995.

Antología. 1916-1953. Pablo de Rokha, ed. Santiago: Multitud, 1954.

Arenga sobre el arte. Santiago: Multitud, 1949. 
"Estimativa y método". Antología de poesía chilena nueva. Eduardo Anguita, Volodia Teitelboim. Santiago: Zig-Zag, 1935.

\section{EsTUDIOS CRÍTICOS Y TEÓRICOS}

Bürger, Peter. Teoría de la vanguardia. Buenos Aires: Los cuarenta, 2009.

Chartier, Roger. El mundo como representación. Barcelona: Gedisa, 1999. Cap. 2.

Ferrada, Ricardo. "La vanguardia literaria: una instancia formativa del discurso crítico latinoamericano". Revista Literatura y Lingüística $\mathrm{N}^{\circ} 18$ (2007): 121-133. Impreso.

Ferreira de Cassone, Florencia. Claridad y el internacionalismo americano. Buenos Aires: Heliasta SRL, 1998.

Ferrero, Mario. "Pablo de Rokha". Revista Atenea No 421-422 (1968): 245-249. Impreso.

Foucault, Michel. El orden el discurso. Barcelona: Tusquets, 2002.

Mariaca, Guillermo. El poder de la palabra. Ensayos de la modernidad crítica latinoamericana. La Habana: Cuadernos Casa, 1993.

Mariátegui, José Carlos. "El proceso de la literatura". 7 ensayos de interpretación de la realidad peruana. Lima: Amauta, 1970.

Möller, Claudia. "Entre Foucault y Chartier: hacia la construcción del concepto de apropiación". Tiempos modernos. Revista electrónica de historia moderna. Año 1 Vol. 2 № 3, 2001. www.tiemposmodernos.org/include/getdoc.php?id=69article $=14$ mode $=$ pdf.

Nómez, Naín. Pablo de Rokha. Una escritura en movimiento. Santiago: Ediciones documentas, 1988.

Nómez, Naín, Manuel Alcides Jofré. Neruda-de Rokha. La escritura total. Santiago: Ediciones documentas, 1992.

Osorio, Nelson. Manifiestos, proclamas y polémicas de la vanguardia literaria hispanoamericana. Caracas: Ayacucho, 1988.

Pacheco, Carlos. "Evolución del manifiesto literario de vanguardias literarias hispanoamericanas: del desapego al compromiso". Divergencias: Revista de estudios lingüísticos y literarios. Vol. $4 \mathrm{~N}^{\circ}$ 1, 2006. Impreso.

Subercaseaux, Bernardo. Historia de las ideas y de la cultura en Chile. Santiago: Universitaria. 2004. Tomo III. Primera parte.

Rozas, Daniel. Pablo de Rokha y la revista Multitud. Santiago: Das Kapital, 2014.

Schwartz, Jorge. Las vanguardias hispanoamericanas. Madrid: Cátedra, 1991. 